\title{
Inventory control policies for a polyester company
}

\section{Políticas de control de inventario para una fábrica de poliéster}

BLANCAS-RIVERA, Rubén†*, CRUZ-SUÁREZ, Hugo, TAJONAR-SANABRIA, Francisco Solano and VELASCO-LUNA, Fernando

\author{
Benemérita Universidad Autónoma de Puebla, Facultad de Ciencias Físico Matemáticas
}

ID $1^{\text {st }}$ Author: Rubén, Blancas-Rivera / ORC ID: 0000-0003-3207-7224, CVU CONACYT ID: 772747

ID $1^{\text {st }}$ Coauthor: Hugo, Cruz-Suárez / ORC ID: 0000-0002-0732-4943, CVU CONACYT ID: 202875

ID $2^{\text {nd }}$ Coauthor: Francisco Solano, Tajonar-Sanabria / ORC ID: 0000-0001-6064-667, CVU CONACYT ID: 34322

ID $3^{\text {rd }}$ Coauthor: Fernando, Velasco-Luna / ORC ID: 0000-0002-8616-8378, CVU CONACYT ID: 75245

DOI: $10.35429 / J I O .2019 .4 .3 .7 .13$

Received March 28, 2019; Accepted June 30, 2019

\begin{abstract}
In this paper, we study an inventory control model, which is analyzed by means of a difference equation. This model is applied to study the stock of a polyester company. In this company, two types of polyester are manufactured, and it is considered a stochastic demand. In the paper, an optimal policy of production is determined, which minimizes the total expected discounted cost. The one-step cost function is integrated with the following components: production, storage and sale lost. The methodology consists on applied the dynamic programming approach and some results of convex analysis to determine a (R, Q)-optimal policy, where $R$ and $Q$ are positive numbers. $R$ represents the maximum level of production and $\mathrm{Q}$ is the minimum stock. Finally, with a company database of monthly sales, we adjust a probability distribution and present a numerical implementation of the optimal. Furthermore, simulations to observe the asymptotic behavior of the stock are illustrated.
\end{abstract}

Inventory control systems, Markov decision processes, Dynamic programming

\begin{abstract}
Resumen
En este trabajo, estudiamos un modelo de control de inventarios, el cual se analiza mediante una ecuación en diferencias. Este modelo se aplica para estudiar el stock de una fábrica de poliéster. En esta empresa se fabrican dos tipos de poliéster y se considera una demanda estocástica. En el trabajo, se determina una política de producción óptima, que minimiza el costo total descontado esperado. La función de costo de un paso se integra con los siguientes componentes: producción, almacenamiento y ventas perdidas. La metodología consiste en aplicar el enfoque de programación dinámica y algunos resultados del análisis convexo para determinar una política óptima $(\mathrm{R}, \mathrm{Q})$, donde $\mathrm{R}$ y $\mathrm{Q}$ son números positivos. $\mathrm{R}$ representa el nivel máximo de producción y $\mathrm{Q}$ es el stock mínimo. Finalmente, con una base de datos de ventas mensuales de la compañía, ajustamos a una distribución de probabilidad y presentamos una implementación numérica de la política óptima. Además, se ilustran simulaciones para observar el comportamiento asintótico del stock.
\end{abstract}

Sistemas de control de inventario, Procesos de decisión de Markov, Programación dinámica

Citation: BLANCAS-RIVERA, Rubén, CRUZ-SUÁREZ, Hugo, TAJONAR-SANABRIA, Francisco Solano and VELASCO-LUNA, Fernando. Inventory control policies for a polyester company. Rinoe Journal-Industrial Organization. 2019. 3-4: 7-13

\footnotetext{
*Correspondence to Author (rublan.fcfm@gmail.com)

$\dagger$ Researcher contributing first author.
} 


\section{Introduction}

In this work we pose an inventory management problem, which we will model through a dynamic system in discrete time and seek to find the optimal operating strategy in a polyester factory. Inventory management consists in matching supply with demand. The problem rests in searching for an optimal operating strategy that indicates the amount which will be produced or purchased in each period, to minimize the expected total discounted cost.

Historically, this problem is of quite importance in the theory of operation research. We have a first approach to this area of research with the economic order quantity formula (EOQ), proposed by Ford W. Harris in 1913; this model is applied when considering deterministic demands. On the other hand, when there are stochastic demands, there are several models that study inventory management. The first one was proposed by Scarf in 1960, who studied a dynamic system which models inventory management and demonstrates that the optimal operating strategy is $(R, Q)$ class. After Scarf, other authors followed him and demonstrated for different dynamic systems that the optimal strategy remains being (R, Q) ([4], [5], [11] and [12]).

In this paper, we consider the demands in different periods as: stochastic, independent and identically distributed. In addition, the dynamic system is Markovian-type and can be identified in a Markov decision model. In this way, Markov Decision Process theory (MDP) can be applied [5]. This model is applied to the control of inventories of two types of polyester, where it is important to consider the aforementioned assumptions and without considering deterministic or fixed demands [9]; besides, optimal operating strategies easy to implement are obtained in this work. The main goal is to show that the optimal strategy is of the form $(R$, $Q$ ), also known as reorder point strategies. This kind of strategies consists in producing a level $Q$ in the warehouse if the inventory is below $R$, otherwise, production is not carried out.

The work is structured as follows: first, we show the description of the model, where the dynamic system that will model inventory management is proposed, the objective is to find an optimal operating strategy. Through Markov Decision Process theory, we exhibit the existence of an optimal strategy.
Thus, in the following section we show that the characterization of the optimal strategy is $(R, Q)$ type. As a main result, we modeled the inventory management of a polyester factory which is identified with a dynamic system and we observed that the assumptions necessary to have optimal strategies $(R, Q)$ are met. Finally, we present numerical results of the inventory management of the factory.

\section{Objectives}

Shanghai Tang Fashion Company is a textile industry company. This type of industry is one of the most important manufacturing sectors in Indonesia. Relevant data in [8] mention that the textile industry in Indonesia still faces a series of internal and external problems which mainly consist of planning uncertainty due to exchange rate fluctuations that lead to increased production costs and shortages of qualified human resources. Shanghai Tang Company faces a similar problem in terms of inaccuracy of inventory management with uncertainty in demand; for example: the quantity, color and type of products of the company. Some of the products that the company manages are:

$-\quad$ Benhur polyester burr,
$-\quad$ Donker polyester burr.

The objective of this research is to find an inventory management policy in order to minimize costs and meet the demand of the product. In this way, the following considerations about the inventory system will be assumed: the inventory is reviewed at the beginning of each week and the decision of polyester production is made, at the end of the week, the quantity of the product sold in kilograms is counted and the inventory level is saved. For this, we consider the following variables:

1. The amount of Benhur polyester in kilograms in the inventory during the week $t$ is denoted by $X_{t}^{1}$, and for Donker polyester by $X_{t}^{2}$.

2. The amount of Benhur polyester in kilograms, produced in week $t$ is denoted by $A_{t}^{1}$, and for Donker by $A_{t}^{2}$.

3. The success of having achieved production in the warehouse of Benhur polyester is denoted by $Y_{t}^{1}$, and for Donker polyester by $Y_{t}^{2}$.

BLANCAS-RIVERA, Rubén, CRUZ-SUÁREZ, Hugo, TAJONARSANABRIA, Francisco Solano and VELASCO-LUNA, Fernando. Inventory control policies for a polyester company. Rinoe JournalIndustrial Organization. 2019 
4. The demand at the end of week $t$ is denoted for Benhur polyester by $D_{t+1}^{1}$, and for Donker by $D_{t+1}^{2}$.

In this way, we will model the inventory of each product handled by the company with the equation in differences:

$X_{t+1}^{s}=\left(X_{t}^{s}+Y_{t}^{s} A_{t}^{s}-D_{t+1}^{s}\right)^{+}, s=1,2$

and $t=0,1,2, \ldots$, where $a^{+}:=\operatorname{Max}\{0, a\}$, $s=1$ represents the stock of the Benhur polyester and $s=2$ for the Donker polyester. In addition, we observe that each $X_{t}^{S}, A_{t}^{S}$ are positive, and their range will be denoted by: $X:=X_{S}=$ $[0, \infty)$ y $A=A_{s}:=[0, \infty)$, respectively.

Equation (1) is motivated by the work done by David Lindley [7], applied to the theory of waiting lines. We observe that model (1) follows a stochastic Markovian process [6] and fulfills the following hypothesis:

\section{Hypothesis 1}

For each $\mathrm{s}=1,2$, the sequence $\left\{\mathrm{D}_{\mathrm{t}}^{\mathrm{s}}\right\}_{\mathrm{t}=1,2, \ldots}$ are independent and identically distributed random variables with a continuous distribution function $\mathrm{F}_{\mathrm{s}}$ and a density function $\Delta_{s}$. In addition, $E_{s}\left[D_{t}^{S}\right]<\infty$, with $E_{s}$ the hope operator associated with the distribution function $\mathrm{F}_{\mathrm{s}}$.

The sequence of variables $\left\{Y_{t}^{S}\right\}_{t=0,1, \ldots}$ are independent and identically distributed random variables with Bernoulli distribution with parameter $p_{s}$ and are also independent with the sequence $\left\{D_{t}^{S}\right\}_{t=1,2, \ldots}$ for each $s=1,2$.

In each period, costs are generated in the inventory; these costs are: storage, production and demand costs not supplied or shortages. Through the following function we contemplate all the costs in each type of polyester, for each $\mathrm{s}$ $=1,2$ :

$$
\begin{aligned}
C^{s}(x, a)= & K_{s} 1_{\{a \neq 0\}}+c_{s} a+h_{s} E\left[\left(x+Y^{s} a\right)\right] \\
& +l_{s} E\left[\left(D^{s}-\left(x+Y^{s} a\right)\right)^{+}\right.
\end{aligned}
$$

where

$K_{S}$ is the fixed cost of production,

$c_{S}$ is the cost per kilogram produced,

$h_{s}$ is the cost per kilogram stored,

$l_{s}$ is the cost per kilogram missing.
On the other hand, for each $\mathrm{s}=1,2$ and $\mathrm{t}$ $=1,2, \ldots$ the production of each polyester $A_{t}^{S}$ is not known. Moreover, it can be seen as a random variable with a distribution that changes in each period, denoted by $\pi_{t}$, which depends on the history of the process until period $t$, where we consider $h_{t}=\left(x_{0}, a_{0}, x_{1}, a_{1}, \ldots, a_{t-1}, x_{t}\right)$ as that history. For example: if we are interested in calculating the probability of having a production in the period $t=3$, greater than or equal to 30 kilograms, we calculate:

$\pi_{3}\left(A_{3}^{S} \in[30, \infty) \mid h_{3}\right)$.

On the other hand, because production always takes positive values, the following is satisfied: $\pi_{t}\left(A_{t}^{s} \in[0, \infty) \mid h_{t}\right)=1$, for each $t=$ $1,2, \ldots$. Thus, in each period there is a distribution $\pi_{t}$, and the succession of all these distributions $\pi=\left\{\pi_{t}\right\}_{t=12, . .}$ is known as strategy or operation policy, and the set of all strategies is denoted by $\Pi$.

A particular case of an operation strategy is Markovian stationary deterministic policies (SDP), which have the characteristic: $\pi_{t}\left(A_{t}^{S}=\right.$ $\left.f\left(x_{t}\right) \in[0, \infty) \mid h_{t}\right)=1$, for some measurable function $f: X \rightarrow A$. We note that this kind of policy has the main characteristic of having a simple implementation, since it does not involve a probability distribution and only requires the correspondence rule $f$. An example of an SDP strategy is those of type $(R, Q)$ with $R \leq Q$, defined as follows:

$f(x)=\left\{\begin{array}{l}Q-x \text { if } x \leq R \\ 0 \text { if } x>R\end{array}\right.$

The model presented in equation (1) induces a stochastic process $\left\{X_{t}^{S}\right\}$ with probability distribution $\mathbb{P}_{S},\left\{A_{t}^{S}\right\}$ is also a stochastic process that depends on the probability distributions given in a $\pi_{s}$ policy. Thus, there is a problem regarding the probability measure which involves all these distributions. First, we define the stochastic process sample space $\left\{X_{t}^{s}\right\}$,

$\Omega:=(X \times A)^{\infty}$,

with $F$ its corresponding $\sigma$-algebra product. The elements of $\Omega$ are of the form

$\omega=\left(x_{0}, a_{0}, x_{1}, a_{1}, \ldots\right)$

with $x_{t} \in \mathrm{X}$ and $a_{t} \in \mathrm{A}$ for each $\mathrm{t}=0,1,2, \ldots$ 
Let $\pi=\left\{\pi_{t}\right\} \in \Pi, \mathrm{s}=1,2$ and an initial state $X_{t}^{s}=x \in X$, then by the Ionescu-Tulcea Theorem [1], there is only one probability measure $P_{x, s}^{\pi}$ in $(\Omega, F)$ such that

$P_{x, s}^{\pi}\left(A_{t}^{s} \in C \mid h_{t}\right)=\pi_{t}\left(C \mid h_{t}\right)$,

$P_{x, s}^{\pi}\left(X_{t}^{s} \in B \mid h_{t}, a_{t}\right)=\mathbb{P}_{s}\left(B \mid x_{t}, a_{t}\right)$,

for each $t=1,2, \ldots$. The stochastic process $\left(\Omega, \mathcal{F}, P_{x, s}^{\pi},\left\{X_{t}^{S}\right\}\right)$ is called the Markov Decision Process at discrete time [6]. The hope with the measure $P_{x, s}^{\pi}$ is denoted by $E_{x, s}^{\pi}$.

The costs generated in the management of the inventory system at an infinite or longterm horizon can be observed with the following function, for $s=1,2$

$V(s, \pi, x):=E_{x, s}^{\pi}\left[\sum_{t=0}^{\infty} \alpha^{t} C^{s}\left(X_{t}^{s}, A_{t}^{s}\right)\right]$

where $\alpha \in(0,1)$ is called a discount factor and means bringing the cost to current value. defined

Then, the optimal value function is

$V^{*}(s, x):=\inf _{\pi \in \Pi} V(s, \pi, x)$,

for each $\mathrm{x} \in \mathrm{X}$. To the policy $\pi^{*}$ that satisfies

$V^{*}(s, x)=V\left(s, \pi^{*}, x\right)$,

(4) is known as

an optimal policy or strategy.

The main objective is to find the optimal strategy that satisfies (4) and that it is SDP and $(\mathrm{R}, \mathrm{Q})$ type.

\section{Methodology}

To find the optimal strategy and the optimal value function (4), we will use the dynamic programming methodology, which consists in dividing the original problem [2] in subproblems. This methodology allows us to find both the optimal value function $V^{*}$ and the optimal strategy $\pi^{*}$.

In order to apply dynamic programming, we first observe that the problem is well defined, that is, that the optimal value function is finite. For this, we use the SDP strategy of never producing in each period, i.e., $f(x)=0, x \geq 0$, so it is not difficult to see that for $s=1,2$ :

$V(s, f, x)<\infty$.
Thus, by (4) we have $V^{*}(s, x)<\infty$

The following theorem exposes the existence of an optimal SDP strategy and an approximation to the optimal value function $V^{*}$. The proof of the Theorem can be consulted in [6].

\section{Theorem 1}

1. There is an optimal SDP strategy for the optimal control problem in model (1).

2. The functions of iterations of optimal values are defined for each $x \in X, s=1,2$ and $n=1,2, \ldots$,

$$
V_{n}(s, x)=\min _{a \in A(x)}\left\{C^{s}(x, a)+\alpha E_{s}\left[V_{n-1}\left(X_{1}^{s}\right)\right]\right\},
$$

with $V_{0}(s, x)=0$, then $V_{n} \uparrow V^{*}$ and the function $V^{*}$ satisfies the following functional equation $V^{*}(s, x)=\min _{a \geq 0}\left\{C^{s}(x, a)+\alpha E\left[V^{*}\left(X_{1}^{s}\right)\right]\right\}$ for each $x \in X$.

\section{Observation:}

1. Equation (5) has the nature of being a dynamic programming equation, since the original optimization problem is divided into optimization subproblems in each period and in the end we get the convergence to the optimum value function.

2. Using the definition of the cost function (2), the value iteration functions (5), can be written as follows:

$$
\begin{aligned}
& V_{n}(s, x)=\min \left\{K+G_{n}(x), \inf _{a>0}\left\{G_{n}(x+a)\right\}\right\} \\
& +H_{n}(x) \text {. }
\end{aligned}
$$

With

$$
G_{n}{ }^{s}(s, x+a):=\left(c_{s}+h_{s} p_{s}\right)(x+a)
$$$$
+\alpha p_{s} E\left[V _ { n } \left(s,\left(x+a-D^{s}\right)^{+}\right.\right.
$$$$
\left.+p_{s} E\left[\left(D^{s}-(x+a)\right)^{+}\right],\right](6)
$$

and

$$
\begin{aligned}
& H_{n}(s, x):=\left(h_{s}\left(1-p_{s}\right)-c_{s}\right) x \\
& \quad+\alpha\left(1-p_{s}\right) E\left[V_{n}\left(s,\left(x-D^{s}\right)^{+}\right)\right] \\
& +\left(1-p_{s}\right) E\left[\left(D^{s}-x\right)^{+}\right] .
\end{aligned}
$$

\section{Results}

The following result on convex functions is an important tool to characterize the optimal strategy and its proof can be consulted in [5]. 
Lemma 1. If $g: \mathbb{R}^{+} \rightarrow \mathbb{R}$ is a convex function and $g(y) \rightarrow \infty$ when $y \rightarrow \infty$, then, there are $R$ and $Q$ scalars with $R \leq Q$ such that

a) $g(Q) \leq g(y)$ for each $y \geq 0$,

b) $g(Q)+K=g(R)<g(y)$ for each $y \geq$ 0

c) $g(y)$ is a decreasing function in $(-\infty, R)$,

d) $g(y) \leq g(z)+K$ for each $y, z$ with $R \leq y \leq z$.

The following theorem shows that the $V_{n}$ functions satisfy the hypotheses of Lemma 1. The proof of Theorem 3 can be consulted in [4].

Theorem 3. Considering Hypothesis 1, for each $n=1,2, \ldots$ the function $V_{n}$ fulfills:

1. $V_{n}$ is convex in $[0, \infty)$,

2. $\lim _{x \rightarrow \infty} V_{n}(s, x)=\infty$.

In this way, for a horizon $n=1,2, \ldots$, the optimal operating strategy is $\left(R_{n}, Q_{n}\right)$ class.

Finally, using $V_{n} \uparrow V^{*}$, equation (5) and the previous lemma, we have the following result. The proof of Theorem 4 can be consulted in [4].

Theorem 4. The SDP strategy which solves (4) is $(\mathrm{R}, \mathrm{Q})$ class.

Therefore, we can apply the SDP strategy to inventory management of each type of polyester, and give values for $R$ and $Q$.

In [8], an inventory study is presented during 2014. First, we observed the efficiency of placing in the warehouse what is required to produce each week. The results are:

\begin{tabular}{|c|l|l|}
\hline Product & \multicolumn{1}{c}{ Benhur } & Donker \\
\hline Efficiency & $85 \%$ & $80 \%$ \\
\hline
\end{tabular}

Table 1 Eficiencia

Each success or failure to place the product in the warehouse must be independent and, in addition, each implementation $Y_{t}^{1}$ has a Bernoulli distribution with parameter $p_{1}=0.85$, and $Y_{t}^{2}$ Bernoulli with parameter $p_{2}=0.80$.
However, for each type of polyester there are independent demands each month. Based on the data presented in [8], we considered the records of the demands in the first 50 weeks of 2014. Table 2 shows the behavior of the demands in kilograms of some weeks.

\begin{tabular}{|l|r|r|}
\hline Demand (kg) & Benhur & Donker \\
\hline Week 1 & 229 & 632 \\
\hline Week 2 & 253.9 & 554.4 \\
\hline Week 3 & 266 & 495.9 \\
\hline Week 5 & 248.5 & 407.1 \\
\hline Week 10 & 191.11 & 380.3 \\
\hline Week 20 & 200.7 & 350.5 \\
\hline Week 30 & 306.5 & 392.8 \\
\hline Week 40 & 332.5 & 461.7 \\
\hline Week 50 & 130 & 356.8 \\
\hline
\end{tabular}

Table 2 Demanda

With the data obtained from the demands in 2014, we made an adjustment to a probability distribution. Using the Kolmogorov Smirnov test [10], the demand for each polyester is adjusted to a normal and uniform mixed distribution with their respective parameters.

\begin{tabular}{|l|c|c|}
\hline Demand/polyester & Benhur & Donker \\
\hline Uniform $(\mathrm{a}, \mathrm{b})$ & $a=234$ & $a=426.8$ \\
& $b=268$ & $b=625.1$ \\
\hline Normal $\left(\mu, \sigma^{2}\right)$ & $\mu=266.3$ & $\mu=452.3$ \\
& $\sigma^{2}=1.7$ & $\sigma^{2}=16.8$ \\
\hline Confidence level & $94 \%$ & $97 \%$ \\
\hline
\end{tabular}

Table 3 Distribución de la demanda

In this way, Hypothesis 1 is satisfied.

We looked for the cost function (2). In Table 3 we present the fixed production costs, per ordered or produced unit of storage, and shortage per kilogram.

\begin{tabular}{|c|c|c|}
\hline Product & Benhur & Donker \\
\hline Fixed order cost & $K_{1}=52.3$ & $K_{2}=95.6$ \\
\hline Cost per order & $c_{1}=144.3$ & $c_{2}=340.8$ \\
\hline Cost per storage & $h_{1}=321.2$ & $h_{2}=340.8$ \\
\hline Short & $l_{1}=197.2$ & $l_{1}=169.2$ \\
\hline
\end{tabular}

Table 4 Costos

According to (2), the cost functions for each polyester are expressed as follows:

\section{Benhur}

$C^{1}(x, a)=K_{1} 1_{\{a \neq 0\}}+c_{1} a+h_{1} E[(x+$
$\left.\left.Y^{1} a\right)\right]+l_{1}{ }^{1} E\left[\left(D^{1}-\left(x+Y^{1} a\right)\right)^{+}\right]$ 


\section{Donker}

$C^{2}(x, a)=K_{2} 1_{\{a \neq 0\}}+c_{2} a+h_{2} E[(x+$ $\left.\left.Y^{2} a\right)\right]+l_{2} E\left[\left(D^{2}-\left(x+Y^{2} a\right)\right)^{+}\right]$.

Once identifying the variables involved in model (1), and complying with Hypothesis 1, Theorem 4 is applied and we obtain a policy $(R$, $Q)$ class for a finite horizon.

Estimates of the optimal value functions (5) are made in each period, $n=1,2, \ldots, 52$ and the values of $R_{n}$ and $Q_{n}$ that characterize the optimal policy. Let us remember that $Q_{n}$ is the minimum of the $G_{n}$ function defined in (5). The value of $R_{n}$ is calculated by solving the equation given in Lemma 1:

$G_{n}\left(Q_{n}\right)+K=G_{n}\left(R_{n}\right)$

In the following table we show the results using the discount factor $\alpha=0.9$ for each polyester.

\begin{tabular}{|l|c|c|}
\hline \multicolumn{1}{l}{ Week } & \multicolumn{1}{c|}{$R_{n}$} & $Q_{n}$ \\
\hline 1 & 287.5 & 298.3 \\
\hline 2 & 287.8 & 298.9 \\
\hline 10 & 289.6 & 299.2 \\
\hline 20 & 289.8 & 299.3 \\
\hline 30 & 290.1 & 299.3 \\
\hline 40 & 290.5 & 299.3 \\
\hline 50 & 290.7 & 299.3 \\
\hline
\end{tabular}

Table 5 Política óptima para Benhur

\begin{tabular}{|l|c|r|}
\hline \multicolumn{1}{|l|}{ Week } & \multicolumn{1}{c|}{$R_{n}$} & $Q_{n}$ \\
\hline 1 & 431.2 & 632.87 \\
\hline 2 & 433.5 & 633.8 \\
\hline 10 & 431.9 & 634.1 \\
\hline 20 & 432.1 & 635.9 \\
\hline 30 & 432.1 & 635.9 \\
\hline 40 & 432.4 & 636.2 \\
\hline 50 & 434.5 & 637.0 \\
\hline
\end{tabular}

Table 6 Política óptima para Donker

\section{Conclusions}

According to the results, we have the following recommendations to obtain the optimal cost at the end of the year.

For Benhur polyester, if it has a capacity of less than $287.5 \mathrm{~kg}$, it is requested to produce the quantity necessary to reach $299.3 \mathrm{~kg}$. Otherwise, no production is requested.
For Donker polyester, more kilograms of this type of polyester are produced until $431.1 \mathrm{~kg}$ is in stock, provided that the stock is below $637 \mathrm{~kg}$. Otherwise, no production is requested.

This shows the importance of having optimal policies (SDP) belonging to $(R, Q)$ class, since they present an easy solution to apply to an inventory system, as in the case of this polyester company.

\section{References}

[1] Ash, R. B., Robert, B., Doleans-Dade, C. A., \& Catherine, A. (2000). Probability and measure theory. Academic Press.

[2] Bellman, R. (1966). Dynamic programming. Science, 153 (3731), 34-37.

[3] Blancas R. \& Cruz, H. (2016). Caracterización de políticas óptimas $(\mathrm{s}, \mathrm{S})$ para una clase de procesos de decisión de Markov (Master's thesis). Facultad de Ciencias Físico Matemáticas, Benemérita Universidad Autónoma de Puebla, Puebla, Puebla.

[4] Daduna, H., Knopov, P. S., \& Tur, L. P. (1999). Optimal strategies for an inventory system with cost functions of general form. Cybernetics and Systems Analysis, 35(4), 602-618.

[5] Feinberg E., Lewis E. (2015). On the convergence of optimal actions for Markov decision processes and the optimality $(\mathrm{s}, \mathrm{S})$ policies for inventory control. http://arxiv.org/pdf/1507.05125v1.pdf

[6] Hernández-Lerma, O., \& Lasserre, J. B. (2012). Discrete-time Markov control processes: basic optimality criteria. Springer Science \& Business Media.

[7] Lindley, D. V. (1952). The theory of queues with a single server. In Mathematical Proceedings of the Cambridge Philosophical Society, 4(2), 277-289.

[8] Margono, S., \& Lestari, Y. D. (2015). Determine the appropriate inventory model in Tang company. Journal of Business and Management, 4(4), 501-509. 
[9] Mármol Vera, M. A. (2019). Estrategias de producción para el mercado local "Slow Fashion frente al Fast Fashion" (Master's thesis, Universidad Técnica de Ambato. Faculty of Design and Architecture. Master's in design, Development and Innovation of Fashion Clothing).

[10] Wasserman, L. (2006). All of nonparametric statistics. Springer Science \& Business Media.

[11] Porteus, E. (1971). On the optimality of generalized $(\mathrm{s}, \mathrm{S})$ policies. Management Science, 17(7), 411-426.

[12] Veinnott A., Wagner H. (1965). Computing optimal $(\mathrm{s}, \mathrm{S})$ inventory policies. Management Science, 11(5), 525-552. 